\title{
Representaçôes sociais e hanseniase em São Domingos do Capim: um estudo de caso na Amazônia
}

| 1 Anete Umbelina Ferreira de Almeida Lins |

Resumo: Este estudo analisa as representações sociais da hanseníase em São Domingos do Capim-PA, a partir da perspectiva da antropologia da doença. As representações são compreendidas como estruturas dinâmicas socialmente construídas que fundamentam as ações dos sujeitos e dos grupos na resolução dos episódios de doença e na produção de sentido para as experiências de adoecimento. Para compreender a lógica das interpretações da doença, foram reconstituídos os itinerários terapêuticos dos doentes, a partir de dados coletados na observação de campo, realizada ao longo de quatro anos, e entrevistas narrativas com doentes, familiares e agentes comunitários de saúde. Foram deduzidas quatro categorias nosológicas êmicas referentes aos sintomas da hanseníase - "manchas", "lepra", "feitiço" e "hanseníase" -, que constituem o repertório a partir do qual as interpretações e práticas são formuladas. O uso das diferentes categorias ocorre segundo esquemas locais que permitem a avaliação dos contextos pessoal e social de irrupção da doença numa dinâmica que articula as percepções do doente e de seus familiares, as interpretações e diagnósticos de curadores tradicionais e a abordagem dos profissionais da Biomedicina. O estudo mostra que o repertório interpretativo e os meios terapêuticos da Biomedicina são reinterpretados, pelos doentes, segundo a lógica das representações e das práticas locais de saúde, e que o controle da endemia hansênica pressupõe a compreensão das dinâmicas sociais implicadas nas interpretaçôes e práticas da doença, de forma a possibilitar o estabelecimento de uma relação dialógica entre os profissionais de saúde e os atores locais.

1 'Médica da Prefeitura Municipal de Barcarena-PA, mestre em Saúde Coletiva. Endereço eletrônico: anetelins@gmail.com. 
A hanseníase caracteriza-se pela multiplicidade de sintomas e sinais. A Biomedicina ${ }^{1}$ classifica a diversidade de manifestações em quatro formas clínicas, segundo critério de predominância de um ou outro sintoma. Assim, na forma tuberculóide, há o predomínio de lesões do tipo placas; a virchowiana, por sua vez, caracterizase pela vermelhidão, infiltração (como inchaço) da pele de forma disseminada; a dimorfa caracteriza-se por lesōes avermelhadas, infiltradas nas bordas, apresentando tamanhos variados e estando, às vezes, agrupadas e numerosas, com aspecto de queijo tipo suíço. A última forma clínica é a indeterminada, quando as manifestaçôes caracterizam-se por manchas geralmente brancas (TALHARI; CRUZ; CARNEIRO, 1997).

Além dessas manifestações na pele, há acometimento dos nervos periféricos, localizados principalmente nos membros superiores e inferiores, na face e no pescoço. Outras manifestações podem surgir antes, durante ou depois da poliquimioterapia, os chamados quadros reacionais do tipo I e II. Caracterizam-se por dores, intensas, generalizadas ou localizadas nas articulações. Na pele podem aparecer nódulos muito dolorosos, e avermelhados. Algumas vezes o doente pode apresentar febre elevada, fraqueza intensa e piora do estado geral. A diversidade de manifestações concorre para múltiplas possibilidades de interpretação, levando frequentemente à confusão com outras doenças e para diagnósticos tardios ou errôneos (BRASIL/MS, 2002).

As condições específicas que determinam o surgimento da doença não são totalmente conhecidas; supõe-se que fatores genéticos ativados por condições ambientais propícias e, principalmente, fatores imunológicos estão na base do processo de adoecimento. Não obstante os avanços que contribuem para esclarecer as condições específicas que determinam o surgimento doença, as pesquisas ainda são inconclusivas a esse respeito (SARNO, 2003).

A despeito das muitas iniciativas colocadas em curso para diagnosticar e tratar os doentes, o aumento na detecção de casos novos aponta para a permanência das condições responsáveis pela alta prevalência da doença no Brasil, em especial na Amazônia. ${ }^{2} \mathrm{Na}$ última década, a expansão da atenção básica de saúde, principalmente através do Programa de Saúde da Família (PSF), teve como um dos objetivos o enfrentamento da alta prevalência de doenças endêmicas, entre elas a hanseníase, nos municípios que contavam com menor infraestrutura de saúde. 
Assim, ao mesmo tempo em que cresce o número de doentes diagnosticados e tratados com a poliquimioterapia, ocorre um aumento no número de pacientes que abandonam o tratamento, ou mesmo que se recusam a iniciá-lo, conforme presenciamos algumas vezes em São Domingos do Capim-PA. Esse fato se relaciona à complexidade social implicada no adoecer de hanseníase.

À complexidade biofisiológica da hanseníase soma-se a polissemia das interpretações, gerando um conjunto de práticas que fazem uso, tanto de elementos das terapias tradicionais, quanto dos repertórios da Biomedicina. Compreender a hanseníase em São Domingos do Capim-PA requer, portanto, desvendar a lógica dessas interpretaçóes, possível apenas por meio de uma abordagem ao mesmo tempo detalhada e abrangente. Afirmamos isso com base nas observações realizadas ao longo de cinco anos de trabalho em São Domingos do Capim, como médica no PSF. ${ }^{3}$

Na tentativa de compreender as questóes queenvolvem a hanseníase, percebemos que o cumprimento de metas de redução da prevalência da hanseníase perpassa dimensões que ultrapassam a abordagem clínica da doença. Assim, o controle da endemia não depende unicamente da expansão da cobertura dos programas sanitários, mas implica o equacionamento de outras questôes envolvidas no adoecimento. Nesse sentido, a antropologia da doença constitui instrumento teórico que favorece a compreensão das dinâmicas da doença segundo uma perspectiva ampla. A doença é entendida com representação, ou seja, como uma construção social dinâmica determinada por processos históricos e sociais inerentes a um dado conjunto social. As representaçôes da doença constituem o substrato sobre o qual os indivíduos formulam suas interpretações e dão sentido a suas experiências (LANGDON, 1995).

As representações se evidenciam pelos discursos e condutas adotadas e, dessa forma, são passíveis de apreensão quando o pesquisador acompanha as trajetórias dos doentes na busca de resolução para sua doença. Partindo dessa perspectiva, este estudo tem como objetivo analisar as representações sociais da hanseníase em São Domingos do Capim-PA, aproximando-se da Antropologia, uma vez que se utiliza dos instrumentos teórico-metodológicos fornecidos pela disciplina, no intuito de compreender os processos sociais implicados na formulação das interpretaçôes da doença nesse meio social, buscando respostas às seguintes questôes: (1) quais categorias nosológicas são utilizadas para classificar as 
manifestações clínicas da doença? (2) Quais sintomas ou sinais são vinculados à hanseníase? (3) Quais causas, agentes ou conjunturas são atribuídas como responsáveis pela irrupção da doença? (4) Como as concepções nosológicas e etiológicas orientam a busca de soluções terapêuticas?

A análise, procurando ultrapassar a simples descrição das concepções locais de hanseníase, busca ainda compreender como a eficácia cognitiva das categorias êmicas permite formular registros interpretativos cujos significados culturais sustentam formas específicas de apropriação da doença pela sociedade, que contribuem para a manutenção da ordem social, a proteção das identidades e a interação entre indivíduos e grupos. Nessa perspectiva, o estudo propõe uma análise do papel desempenhado pela Biomedicina, considerando que esta se pretende como única instância de legitimação do diagnóstico e de produção de verdades, no que se refere ao corpo e à doença. $\mathrm{O}$ trabalho pretende, assim, analisar as interações e relações produzidas a partir dos significados estruturados pelas representações, assim como perceber como esses significados engendram práticas de diagnóstico e tratamento, além de tentar compreender como contribuem para formular relaçōes sociais e identidades num contexto de convívio muito próximo com a Biomedicina, mas de permanência dinâmica de valores tradicionais.

\section{O contexto etnográfico}

Os aspectos da formação étnica da população rural ribeirinha de São Domingos do Capim tiveram sua origem de negros escravos africanos, indígenas e portugueses. Os negros foram levados para estas áreas que eram de agricultura intensiva e comércio de produtos agrícolas como o cacau, fumo e algodão no mesmo período da política pombalina, ocasião em que foi criada a Companhia Geral do Comércio do Grão-Pará e Maranhão (1755), quando veio um número considerável de escravos negros para a região (CAYRES, 1999).

A formação histórica e cultural de São Domingos do Capim se assemelha às de outros povoados que surgiram na região do Grão-Pará e Maranhão, influenciados por essa política de colonização. As atividades que encontramos ainda hoje conservam os traços culturais daquele período, refletindo a herança de mais de dois séculos dessas misturas, destacando-se as práticas de caçar, pescar, queimar a mata para o plantio, cultivar mandioca, milho e feijão, bem como de denominar a flora, a fauna e as localidades com termos de origem indígena. As 
influências na culinária, no imaginário como lendas e mitos, música e o tipos de habitação e moradia, são exemplo disso.

A inserção de São Domingos do Capim no contexto da Amazônia e, em particular, do estado do Pará, adquire nova configuração a partir das décadas de 1960 e 1970, com a implantação dos grandes eixos rodoviários de integração nacional. Nesse caso, interessa citar a BR-316 (Pará-Maranhão) e a BR-010 (Belém-Brasília), que representaram, na época, um profundo processo de reorganização espacial na região, produzindo uma relocalização do município na hierarquia dos circuitos regionais de produção, circulação e consumo, com impacto sobre as formas de ocupação do território e sobre as relações sociais. A abertura das estradas inaugura novas dinâmicas econômicas, sociais e espaciais. Nossa hipótese é que a cidade tomou uma posição secundária nas redes de fluxos econômicos, fato que se evidencia quando, ao conversar com moradores mais antigos, surgem referências a atividades e práticas não mais existentes e que são reminiscências de relações estruturadas em outros tempos.

Essas falas dão notícias do regime de patronato vigente ao longo dos dois grandes rios e de seus afluentes. O "patrão", geralmente proprietário de embarcação chamada de regatão - para o comércio itinerante dos rios da Amazônia - financiava a produção da pequena lavoura de mandioca e confecção da farinha ou extrativismo de recursos da floresta, em troca de roupas e alimentos industrializados e equipamentos. A cidade atuava como grande entreposto para trocas entre esses comerciantes e outros intermediadores, que faziam os produtos chegarem a Belém. Ficam evidentes as fortes relações que uniam diferentes locais ao longo dos rios São Miguel do Guamá, Santana, Belém e um conjunto de pequenas comunidades dispersas por toda a bacia. A abertura das estradas cortando todo o município alterou drasticamente as relações econômicas na medida em que atraíram novos atores sociais, como fazendeiros e madeireiros, motivados pelas possibilidades de exploração de recursos florestais e pela aquisição de terras para pecuária e cultivo de pimenta-do-reino.

No início dos anos 80 do século XX, havia surgido no território do município núcleos urbanos ao longo da BR-010, que rivalizavam em tamanho e importância com a sede municipal e atraíam consideráveis fluxos migratórios e também de capitais para esse eixo. $\mathrm{Na}$ verdade, existiam poucas relações entre as dinâmicas em curso ao longo da rodovia e aquelas tradicionalmente desenvolvidas ao longo do rio Capim. 
A região de influência direta dos rios Capim e Guamá, próximos à cidade de São Domingos, caracteriza-se pela permanência das antigas dinâmicas em que prevalecem a agricultura de subsistência, o extrativismo vegetal (do açaí) e da comercialização da farinha de mandioca, a despeito das dinâmicas em curso ao longo das áreas de influência dos grandes eixos rodoviários, que apresentavam rápidas transformaçōes na configuração das relaçōes sociais e econômicas. A feira, que acontece todas as quintas-feiras, marca bem essas dinâmicas, convergindo a este local produtores rurais de todo o município, para comercialização da farinha e aquisição de outros produtos que são trazidos em grande parte por comerciantes de outros municípios, como roupas, brinquedos, eletrodomésticos, utensílios do lar e alimentos. São Domingos do Capim é hoje um local onde predomina a economia de subsistência, que tem como base a farinha de mandioca.

A cidade ou a "rua", como se referem os moradores do município, possui cerca de $25 \%$ da população total (6.000 habitantes) e congrega uma grande área rural que abrange terras dos municípios de São Miguel do Guamá, Inhangapi e Concórdia do Pará, o que se percebe pelo afluxo de usuários do sistema de saúde e alunos na escolas urbanas, no comércio e na agência bancária.

A década de 90 trouxe algumas mudanças capazes de conferir algumas alterações mais profundas sobre as dinâmicas socioeconômicas em curso: a expansão da educação fundamental, ${ }^{4}$ por meio do aumento do número de vagas e do transporte escolar nas áreas rurais, por exemplo.

Nas comunidades rurais como as de São Domingos do Capim, a vida se organiza temporalmente a partir de dois eventos; a feira na "rua" e a celebração da missa do domingo pela manhã. Segunda, terça e quarta-feira são os dias da preparação da farinha, de colher frutas, de preparar os animais, de colher o açaí, às vezes, de preparar o peixe fresco do rio ou salgados - produtos que serão levados à rua de ônibus ou de barco, embarcados de madrugada e negociados com intermediadores para a venda em Belém-PA, ou vendidos diretamente aos consumidores. No domingo se realiza sempre a celebração - católica ou protestante -, evento de caráter iminentemente local, em que a forte religiosidade se revela uma marca histórica arquitetada desde a colonização da Amazônia. Este dia é um dos mais especiais para as pessoas e para a própria comunidade. Vestemse da melhor maneira possível por vaidade, no entanto sem ostentação, mas por reverência e respeito, considerando o sentimento de pertencimento a uma religião e a uma comunidade religiosa. 
Apresenta práticas e tecnologia semelhantes às utilizadas na época da colonização, herdadas dos índios, sendo este um dos fatores que contribuem para a baixa produtividade das atividades laborais. Outra característica deste sistema de produção agrícola é ser desempenhado por toda família e, pela maioria das pessoas, apesar de estarem ocupadas na roça, somente 57\% dos que trabalham têm renda. Conforme os dados do IBGE publicados pela SEPOF (PARÁ, 2008), em 2005 mais de 43\% têm ocupação não remunerada, isto é, encontram-se na condição de ajudante do membro do domicílio e na produção do próprio consumo, prática esta secular.

A pesquisa foi realizada na área adscrita de atuação do Centro de Atenção à Saúde da Família (CASF - Ponto Certo), que envolve 953 famílias distribuídas em área considerada urbana, o Ponto Certo, e outra considerada rural, conhecida como "comunidade". Esta separação é muito mais espacial do que indicativa do modo de vida das pessoas, hábitos e costumes e a relação com o trabalho.

Para mencionar o perfil e identidade dos doentes, bem como dos passíveis de adoecimento, devemos ter o cuidado de contextualizar os condicionantes sociais. As informações encontradas a partir de uma avaliação preliminar em 29 fichas de notificação de hanseníase, pesquisadas na Secretaria Municipal de Saúde de São Domingos do Capim, no período compreendido entre 2001 e 2006, constituem o material analisado.

Nos últimos anos, mesmo com as limitaçóes e dificuldades, o município tem conseguido construir um perfil epidemiológico nas áreas de implantação de PSF. A detecção de casos de hanseníase, que em 1999 fora apenas de dois casos, em 2001 passou para sete. No ano seguinte, para 17, chegando a 33 casos em 2006. A somatória de todos os casos ao longo deste período totalizou 130 doentes e, destes, 113 eram casos novos. Nos últimos anos, ainda se observa uma tendência de crescimento da endemia. Outro aspecto da endemia é a frequência por classificação operacional dos casos notificados: na proporção entre estas duas classes, há um predomínio de $73 \%$ de casos multibacilares (presença de muitos bacilos) em relação a $27 \%$ de paucibacilares (com poucos bacilos), indicando que os serviços de saúde estão diagnosticando a hanseníase tardiamente. E ainda, a maioria dos casos, quando diagnosticados, o modo de detecção é por demanda espontânea e exame de contatos, e não por busca ativa em exame de coletividade.

A escolaridade das pessoas acometidas por hanseníase, nesse mesmo período, incluía $83 \%$ que estudaram até a antiga sétima série do ensino fundamental. 
Destes, $17 \%$ não têm escolaridade, $24,6 \%$ têm de um a três anos de escolaridade e 40,7\% têm entre quatro a sete anos de permanência na escola.

A distribuição da endemia por sexo revela que a maioria acometida são os homens $58,4 \%$, sendo que as mulheres representam 44,6\%. Portanto, é preciso considerar até que ponto as condições sociais de gênero contribuem para o acometimento maior nos homens do que nas mulheres? Desta forma, atribuímos algumas diferenças quanto aos hábitos de vida que possam contribuir para a predisposição maior nos homens, tais como: deslocamentos mais frequentes, para diferentes frentes de trabalho; ingestão mais frequente de bebidas alcoólicas; menor procura pelos serviços de saúde, o autocuidado com o corpo é menos observado nos homens em relação às mulheres. Vale lembrar que a população masculina é maior neste município em quase 5\%.

Os moradores do Ponto Certo e das comunidades rurais são os sujeitos desta pesquisa. Por vezes, confundem-se com os colegas de trabalho, no caso os Agentes Comunitários de Saúde (ACS) e com os usuários do sistema de saúde, portadores de hanseníase em tratamento, além daqueles que continuamos a acompanhar, como médica, devido às sequelas, estados reacionais, prevenção e controle de incapacidades, bem como suas famílias moradoras da área de abrangência do PSF do Ponto Certo, com quem convivemod diariamente. Trata-se de um grupo populacional que poderia denominar de tradicional, morador de áreas ribeirinhas, predominantemente rural, mas que apresenta influências do contato com modo de vida urbano e moderno.

\section{Afinal, o que é "essa doença”}

As representações estão na base das escolhas realizadas pelos doentes e seus familiares no que diz respeito à terapêutica e demais práticas que envolvem a doença, de forma que cada opção se vincula às interpretaçôes da doença e à maneira como indivíduos constroem o sentido para suas experiências a partir do repertório simbólico de sua sociedade (RAYNAUT, 2001).

Como demonstraram Andras Zempléni (1982) e Dominique Buchillet (1991), as opções terapêuticas são, em grande parte, determinadas pelas possibilidades cognitivas de apreensão do funcionamento das terapias, bem como por sua capacidade de gerar interpretações socialmente coerentes para a doença.

Acompanhamos, por meio de relatos de doentes e familiares, 12 trajetórias de adoecimento de hanseníase, a partir das quais foi possível reconstituir seus 
itinerários terapêuticos e a contínua atualização das interpretações propostas, conforme o quadro patológico evoluía. Serviram também para este fim as observações realizadas durante os atendimentos médicos, as conversas e os relatos dos agentes comunitários de saúde. Partindo dos itinerários terapêuticos, deduzimos quatro categorias nosológicas êmicas associadas às manifestações da hanseníase e, ao que tudo indica, fundamentam o processo de produção do sentido para a doença em São Domingos do Capim. O quadro abaixo mostra essas categorias e os sintomas a elas associados:

\section{Quadiro 1 - Categorias nosológicas êmicas associadas à hanseníase}

\begin{tabular}{|l|l|}
\hline \multicolumn{1}{|c|}{ Categorias nosológicas êmicas } & \multicolumn{1}{c|}{ Sintomas e sinais } \\
\hline $\begin{array}{l}\text { Manchas (mancha de verme, } \\
\text { mancha de sol, impingem, } \\
\text { pano branco) }\end{array}$ & $\begin{array}{l}\text { Manchas brancas, manchas avermelhadas, } \\
\text { manchas descamativas. }\end{array}$ \\
\hline Lepra & $\begin{array}{l}\text { Feridas que comem partes do corpo (nariz, orelhas), } \\
\text { mutilações de extremidades do corpo (dedos, pé, } \\
\text { mão, orelhas, nariz), nódulos subcutâneos. }\end{array}$ \\
\hline Feitiço & Feridas crônicas que doem como ferroadas. \\
\hline Hanseníase & Profusão de manchas grandes e disseminadas. \\
\hline
\end{tabular}

O caráter processual da doença aponta para o fato de que as diferentes categorias nosológicas são associadas a momentos distintos de evolução do quadro patológico. Assim, de forma geral, as "manchas de verme", "manchas de sol", "pano branco" e "impingem" constituem o diagnóstico suscitado pelos sintomas iniciais da doença. Tais categorias são aplicáveis quando as interações entre os doentes, os terapeutas (curadores ou médicos) e o grupo social são mobilizadas pelo agravamento das manchas ou o surgimento de novos sintomas.

A seguir, analisamos como cada categoria nosológica êmica é utilizada e como ela conduz o processo de produção de sentido para o adoecimento dentro de contextos individuais e sociais específicos.

\section{Lepra: uma doença dos "antigos"}

O aumento da detecção do número de casos de hanseníase que diagnosticavamos na unidade de saúde entre os anos de 2003 e 2007 gerava preocupações em toda 
equipe de saúde. Esse sentimento motivou a organização de reuniōes comunitárias para falar sobre a doença e realizar a busca ativa de novos casos. Em todas as reuniões realizadas, empregar termo "hanseníase", algumas pessoas demonstravam desconhecimento sobre a doença e qualquer pessoa doente que tivesse sido acometida por ela. Em algumas situações, explicávamos que a "hanseníase” era um novo nome para a antiga doença denominada de "lepra". Várias vezes ouvimos relatos de casos descritos pelas pessoas mais velhas referindo-se à doença como "coisa dos antigos", não mais existindo em São Domingos do Capim.

Nos relatos dos agentes comunitários de saúde, mas também nas entrevistas e na observação participante, identificamos descrições de ferimentos crônicos que não cicatrizavam, perda de partes do corpo, sendo frequentemente associadas à imagem de Lázaro, da parábola contida no Evangelho de Lucas (Capítulo XVI, vers. 19 a 31). A imagem dos acometidos pela "lepra" vincula-se, assim, a uma figura do imaginário religioso constantemente evocada nos cultos cristãos.

Essas leituras, conforme relataram os agentes comunitários de saúde, são feitas todo ano em todas as Igrejas Cristãs (Católica, Assembleia de Deus, Quadrangular) das quais também participam, associando, assim, essas imagens de Lázaro a outro suposto doente de lepra que há alguns anos mendigava pelas ruas de São Domingos do Capim, conhecido por todos. Não fazem referência só a este doente específico. Referem-se também a outros casos, inclusive de familiares já falecidos e alguns mais novos que permaneceram com sequelas.

Os relatos que ouvimos se referem à lepra como uma doença que promovia a descaracterização dos corpos dos acometidos. Os casos eram descritos mencionando sempre as feridas e a mutilação das extremidades do corpo, alteração da face, do nariz e das orelhas. Em nenhum dos casos relatados há referência às manchas ou sintomas neurológicos, do que se pode concluir que a categoria nosológica "lepra" refere-se aos quadros em que ocorre o aparecimento de feridas e mutilações de partes do corpo.

Para analisar e compreender melhor o uso da categoria "lepra" na interpretação do adoecimento, é necessário analisar as múltiplas atribuições causais a ela associadas, conforme proposto por Nicole Sindzingre e Andras Zempléni (1981). Os itinerários terapêuticos evidenciaram associaçóes causais propostas pelos doentes e seus familiares, quais sejam: trabalhar no cemitério São João 
Batista situado no outro lado do rio e ter pisado descalço na terra (local onde foram sepultadas as pessoas com lepra) e depois apresentar os sintomas; brincar em contato com o assoalho, ou na terra, vestir a mesma roupa suada da pessoa acometida pela doença; compartilhar dos mesmos objetos pessoais (copo, toalha de enxugar a mão); e comer o resto de alimento do prato de outra pessoa. Assim, a causa da lepra associa-se tanto ao contato com a terra, intrinsecamente considerada como fonte de emanações causadoras de doenças, como ao contato com doentes ou ambientes e objetos contaminados, entre eles o solo em que ocorreram o sepultamento de doentes, casas e utensílios utilizados por eles.

A explicação da doença retoma as concepções das teorias telúrica, miasmática e do contágio, em voga nos século XVIII e XIX. Estas teorias representam um retorno às ideias hipocráticas que localizam a doença não no indivíduo, mas no meio ambiente que o envolve, constituindo o que Michael Foucault (1984, p. 92) denominou de "medicina das coisas, medicina das condições de vida e do meio de existência", em oposição à Biomedicina, definida como "medicina dos homens, dos corpos e dos organismos".

A teoria telúrica atribuía a causa das doenças às "emanaçôes malignas do solo" (COSTA, 2002). Esta concepção foi ampliada na teoria miasmática, segundo a qual as doenças seriam produzidas por "miasmas" que resultam das emanações dos processos de decomposição de substâncias orgânicas vegetais, animais ou humanas que corrompiam o ar e afetavam o corpo humano. A natureza, em especial as áreas pantanosas, e as habitações insalubres, seriam o ambiente propício para a produção de miasmas e, consequentemente, das doenças.

A teoria contagiosa postula que a causa das doenças estaria no contagium ou vírus, "um princípio de transmissão mórbida que se reproduzia no organismo humano e podia passar de um a outro" (COSTA, 2002). O contágio poderia ocorrer de forma direta, mas também de forma indireta, pelo ar, pelo contato com vestimentas e outros objetos. Desta forma, os doentes precisavam ser isolados e seus objetos serem segregados e as edificações por eles utilizadas passariam por processos de desinfecção.

Elementos dessas três teorias marcaram as interpretações causais da "lepra" nos relatos de São Domingos do Capim, explicando as práticas de isolamento e segregação social dos doentes presentes em vários itinerários terapêuticos. 
As interpretações tradicionais da doença não se constituem a partir de um repertório de categorias nosológicas predeterminadas, mas a partir de uma dinâmica entre diferentes possibilidades interpretativas sociologicamente coerentes e cognitivamente eficazes (SINDZINGRE; ZEMPLÉNI, 1981).

Para Andras Zempléni (1982), a dinâmica das interpretações da doença conjuga a percepção empírica dos sintomas e das causas em uma "negociação" em que o que está em jogo é a solução de conflitos relacionais e o status social do doente, mais do que a definição de práticas destinadas a por fim ao seu sofrimento físico.

A utilização da categoria êmica "feitiço" evidencia como a interpretação da doença é posta a serviço da "resolução" dos conflitos no interior do grupo a que pertence o doente, ao mesmo tempo em que permite a defesa contra a estigmatização, caso este fosse considerado como acometido pela "lepra".

O caráter multifacetado das manifestações da hanseníase responde por sua capacidade de gerar diferentes interpretaçôes a respeito de um mesmo processo individual de adoecimento. A identificação da doença como feitiço representava também uma resposta à possibilidade de estigmatização e, via de regra, implicava a recusa do tratamento da Biomedicina.

A despeito dos usos sociais implicados nessa interpretação da doença, a constituição do "feitiço" como categoria nosológica êmica se assenta sobre um quadro sintomatológico mais ou menos definido, cuja manifestação permitia ao doente e aos seus familiares reivindicar junto ao grupo social a interpretação de sua doença como um "feitiço" em oposição as interpretações em favor de um diagnóstico de "lepra" ou mesmo de "hanseníase".

Esse quadro sintomático se constitui a partir do aparecimento repentino de dores nas pernas, erupção de feridas que se tornam crônicas ("que não saram") e progressiva perda da capacidade para o trabalho. São comuns, ainda, os relatos de que os tratamentos de curadores consistem na retirada de "bichos" (larvas) dos ferimentos supostamente colocados no corpo do doente por meio do feitiço. $\mathrm{O}$ "feitiço" é entendido como um distúrbio biofisiológico causado pela manipulação de forças mágicas por um agente que intenciona atingir o doente.

Os relatos que atribuíam o estado de adoecimento a um "feitiço" estabelecem a impossibilidade de tratamento do quadro por recursos terapêuticos da Biomedicina. Apenas os curadores e pajés, manipuladores das forças mágicas, 
seriam capazes da resolução do sintoma. A característica fundamental do feitiço é a produção de sintomas que afetam a capacidade física para o trabalho, em maior ou em menor grau. O "feitiço" implica, assim, a ressituação do indivíduo no grupo familiar e no grupo social, embora isto ocorra numa posição menos desfavorável que aquela destinada aos acometidos pela "lepra”. Daí a categoria nosológica "feitiço" ser utilizada como alternativa a categoria "lepra".

O trabalho de Guilhermina Cayres (1999) demonstra que nas comunidades do rio Capim - e pode-se afirmar que pode ser generalizado a todas as comunidades ribeirinhas da Amazônia -, a divisão social do trabalho atribui ao homem as atividades principais que irão garantir o sustento da família (agricultura da mandioca e produção de farinha, comercialização), cabendo às mulheres e às crianças o desenvolvimento das atividades complementares de subsistência, como a criação de pequenos animais ou cultivo de pequenas hortas. $\mathrm{O}$ reconhecimento social do homem está ligado, assim, ao desempenho eficaz do papel de provedor de sustento de seu grupo familiar.

A categoria "feitiço" aparece invariavelmente associada à transgressão das normas do casamento, sendo relacionada à traição. As situações de adultério, frequentemente conhecidas por toda a comunidade, eram tratadas de maneira tácita, no meio familiar, sem que provocassem a eclosão de um conflito relacional aberto no grupo.

De maneira geral, é a irrupção da doença que possibilita a explicitação dos sentimentos envolvidos na situação. A busca por uma interpretação e de um tratamento com um curador local é o que permite essa explicitação, pois o curador atribui o aparecimento dos sintomas a um feitiço preparado pela amante. Essa enunciação provoca o rompimento da relação com a amante e a reaproximação do doente com a família, em uma nova posição (talvez não mais como provedor, mas como alguém que aspira cuidados, ou seja, como alguém que precisa da família), ainda que não ofereça nenhuma possibilidade de reversão do quadro patológico ocasionado pelo feitiço.

\section{Mancha: sujeira na pele ou algo mais}

A mancha é a categoria êmica mais frequentemente encontrada nas entrevistas. É também, do ponto de vista médico, a manifestação biofisiológica mais comum, passível de se fazer diagnósticos diferenciais entre várias doenças de pele, dentre elas a hanseníase. 
As manchas são em geral alterações superficiais, indolores e por isso, inicialmente não incomodam, não parecem suscitar qualquer ameaça à saúde. Assim, são passíveis de serem ignoradas, pois não se atribui importância, principalmente se forem pequenas ou pouco numerosas. As atitudes em relação às manchas podem se atualizar, caso as características se modifiquem com a evolução da lesão, como o aumento de tamanho, do número e a persistência por tempo prolongado, ou quando houver antecedente familiar de hanseníase. Novas interpretaçóes irão surgir e ocasionarão a busca de explicações e resolução para o caso.

Os comportamentos diante de uma mancha podem variar de com o indivíduo acometido e do contexto em que se insere. A constatação de uma mancha pode suscitar diferentes comportamentos e decisões e variar desde uma observação extremamente detalhada, ao longo de dois anos, mesmo que interpretada como "mancha de verme"; e mediante o diagnóstico de hanseníase os envolvidos na atualização dessa interpretação adotarem uma atitude de negação e desconfiança junto ao médico que enunciou. A mancha pode ainda passar despercebida, caso a localização corporal (como dorso e nádegas) esteja inacessível aos olhos do próprio portador.

Outra hipótese de como lidar com o aparecimento de uma mancha pode se caracterizar pela indecisão dos familiares e, desta forma, postergar o esclarecimento do diagnóstico e consequentemente se restringir a lavar vigorosamente por meses, supondo talvez se tratar de uma "sujeira" ou ainda por temer a possibilidade de ser hanseníase. O fato de não buscar explicação ou solução para o caso não significa omissão ou negligência, mas medo da possibilidade dessa e adiá-la, fugindo do confronto, mesmo que sob a angústia da dúvida, até chegar o momento de decidir elucidar o diagnóstico junto ao médico.

O aspecto das lesões cutâneas (cor, tamanho, número e relevo) é determinante para sua classificação como "pano branco" (leucodermias com descamação furfuráceas); "manchas de verme" ou "mancha de sol" (leucodermias com bordos irregulares); impingem (eritema com bordas delimitadas em relevo), que são associadas à doenças de pele muito comuns, respectivamente, ptiríase versicolor, ptiríase alba e tinea corporis (ou tinha do corpo). Essas manifestações são tratadas usando recursos terapêuticos tradicionais (plantas) ou medicamentos prescritos por familiares, curadores ou pela propaganda veiculada na televisão. As manifestações mais persistentes são tratadas com o uso de produtos considerados 
mais potentes para "matar" a infecção e limpar a pele, como o sumo de limão, álcool, amoníaco, pólvora e cachaça aplicados diretamente sobre o local afetado.

As lesões cutâneas da hanseníase apresentam, à primeira vista, semelhança com aquelas apresentadas por essas afecções e, portanto, recebem o mesmo tratamento. Como a aplicação das substâncias não resulta no desaparecimento das manifestaçôes, os doentes recorrem inicialmente ao tratamento de curadores tradicionais, que muitas vezes realizam prescrições de medicamentos da Biomedicina, como o cetoconazol..$^{5}$

A persistência das manifestações cutâneas após a aplicação desses recursos terapêuticos conduz o paciente a recorrer aos agentes comunitários de saúde e posteriormente ao médico. Assim, a forma como as lesões cutâneas são interpretadas passou a sofrer modificações com a atuação do PSF. A relativa familiaridade para acessar os serviços de saúde fazia com que as manifestações cutâneas passassem a motivar consultas médicas, sobretudo pela possibilidade de obtenção de medicamentos de forma gratuita.

O exame atento das manchas propiciou a realização de diagnósticos precoces de hanseníase, quando outros sintomas ainda não haviam se manifestado. As explicações médicas e as prescrições da poliquimioterapia contribuíram para a produção de uma nova possibilidade de diagnósticos para as manchas - a hanseníase. As manchas ganharam, assim, um caráter ambíguo, pelo fato de que podiam ao mesmo tempo indicar afecções simples passíveis de resolução com tratamento tópico, mas também indicar o acometimento por uma nova doença para a qual seria necessário se submeter a um tratamento longo e complexo.

Desta forma, as manifestaçōes cutâneas, antes tratadas com certa indiferença e que mobilizavam senão a atenção e os cuidados caseiros e o recursos a tratamentos tópicos, passaram a ser motivo de outras interpretações e de preocupação, motivando a procura do médico para esclarecimento do diagnóstico.

\section{A hanseníase ou a nova "lepra"}

A análise da categoria êmica "mancha" demonstrou que as manifestaçôes cutâneas, muito comuns em São Domingos do Capim-PA, ganharam um caráter ambíguo após a penetração mais efetiva da ação dos profissionais da Biomedicina.

A ambiguidade na interpretação desses sintomas foi constituída com base na circulação de informações sobre os diagnósticos realizados nas unidades de saúde 
ou nas visitas domiciliares da equipe de saúde, às campanhas informativas do Ministério da Saúde na televisão, ou por meio de cartazes afixados nesses serviços. Essas informações atribuem às manchas o status de sinal característico de uma "nova doença", que na percepção dos doentes se tornava cada vez mais comum no município, como indicavam o comentários de diversos doentes para os agentes comunitários de saúde: "está dando muito essa doença aqui no Capim".

A expressão "essa doença" era comumente utilizada para designar a enfermidade. De início, consideramos que a opção por não utilizar "hanseníase" ou "lepra" se devia à carga de significados negativos que a ambos os termos estava associada. Ainda mais que em relatos de pacientes presentes nos trabalhos de Bakirtzief (1994) e Claro (1995), a omissão dessas designações se fazia em proveito da manutenção das identidades individuais, contra os estereótipos sociais e o estigma.

A ampliação do número de pacientes diagnosticados, com os quais mantínhamos contato freqüente, e mais tarde, a coleta de depoimentos mais sistematizados de doentes, familiares e agentes comunitários de saúde, tornaram evidente que ao utilizarem a expressão "essa doença” para designar a hanseníase, estavam manifestando sua pouca ou nenhuma familiaridade com a terminologia. O que era fácil de se compreender, tendo em vista que o termo "hanseníase" passou a ser utilizado no Brasil, em substituição ao termo "lepra", há pouco mais de 30 anos e se difunde basicamente por meio dos serviços de saúde e campanhas educativas. Bastante ilustrativo é o fato de que comumente não pronunciam o "h" aspirado do início da palavra, substituindo-o por "h" mudo.

A concepção de que o termo "hanseníase" designa uma nova doença unicamente definida e detectada pela Biomedicina acarreta algumas implicações sobre as relaçóes que se instituem entre os profissionais de saúde, curadores tradicionais e a população em geral. Vejamos a seguir cada um destes pontos.

$\mathrm{O}$ primeiro se refere às explicações causais para o adoecimento. Quando inquiridos sobre as causas para o aparecimento da hanseníase, os doentes e seus familiares não estabelecem respostas unívocas ou bem definidas, tal como o faziam para as demais categorias nosológicas, como "lepra", "mancha" ou "feitiço". O que se obtinha frequentemente era o retorno da pergunta: "é a senhora que tem que nos responder”. Para os doentes que atendíamos, explicávamos as causas prováveis da doença, o agente etiológico microbiano, como este afetava o organismo, além das formas de contágio, segundo a perspectiva da Biomedicina. 
Embora ouvissem com atenção e não parecessem ter dúvidas, recorriam aos agentes comunitários de saúde em busca de novas explicações.

No momento em que realizamos as entrevistas, em nenhum momento as categorias explicativas da Biomedicina apareceram. Em seu lugar, uma explicação muito genérica era frequente: "é o destino. Deus quem quis". A atribuição da origem da doença à vontade divina não parecia carregar os significados associados à "lepra" como castigo divino, mas parece, como entre os Senufo, da Costa do Marfim, estudados por Nicole Sindzingre e Andras Zempléni (1981), uma explicação para os agravos em que os esquemas interpretativos locais ainda não haviam determinado causas mais específicas. A constituição das relações causais demanda um longo processo de construção de categorias explicativas, por meio de vivências de adoecimento repetidas entre os diversos membros da comunidade e identificadas como a mesma doença (CORMIER, 2005). Assim, embora em alguns relatos tenham sido construídas associações entre o contato com pessoas doentes ou elementos da natureza (capim peludo, por exemplo) e o surgimento da doença, as conjecturas não estabelecem estas como condiçóes suficientes, mas apenas como condições necessárias para o adoecimento. $\mathrm{O}$ aparecimento da doença é, assim, indissociável dos desígnios divinos.

Desta forma, a incorporação da categoria êmica hanseníase no repertório interpretativo da doença não implicava uma incorporação do modelo de interpretação da Biomedicina, na medida em que não havia apreensão dos esquemas de explicação causal da doença sob essa perspectiva, até porque a aceitação do diagnóstico pela lógica biomédica era um dos pontos de conflito com as interpretações tradicionais.

Observamos inúmeras vezes que pessoas mais jovens e com mais escolaridade, acometidas ou não pela doença, em seus percursos na busca pela explicação para o adoecimento, se aproximavam da lógica biomédica, cuja investigação se materializava por meio de exames laboratoriais (pesquisa direta, na pele, do bacilo causador da hanseníase e na investigação direta de fungos por agentes causadores do pano branco e da impingem). Muitas vezes nos questionavam no consultório se não seria pedido o exame para confirmar o diagnóstico e, na maioria das vezes, lhes era explicado que não era necessário, pois sabíamos, após a avaliação e o exame na pele e nervos, que o resultado iria ser negativo. Explicávamos que no local da colheita do exame nem todas as vezes o agente causador estava presente. 
Somente em poucas pessoas o médico, após examiná-las, saberia diagnosticar quais deveriam ser submetidas ao exame de pesquisa do bacilo. Muitos parentes, não aceitando esses argumentos, procuravam outros médicos no município e faziam os exames (de pesquisas diretas de fungos e do bacilo da hanseníase).

A ideia da negatividade do resultado parecia afastar a possibilidade de estar doente, provocando um desencontro de informações e condutas médicas e, consequentemente, erro diagnóstico, o que acabava por impedir ou atrasar o início do tratamento. Isso nos levava a supor que a expectativa sobre o resultado do exame era o de contrariar e negar o incômodo diagnóstico que enunciávamos. A reação por parte dos prováveis doentes e seus familiares era passível de suscitar sentimento de revolta, desconfiança e negação do diagnóstico, por tudo que a hanseníase representa e pelas consequentes discriminações sofridas por eles.

Apesar da mudança da condição de doente, legalizada através da retirada do nome das estatísticas de prevalência do Programa Nacional de Controle de Hanseníase, após a conclusão terapêutica, isto nunca foi suficiente para uma mudança de identidade dessas pessoas, pois não só continuavam sendo vítimas das sequelas biofisiológicas, muitas vezes provocadas pelos estados reacionais, mas principalmente do ponto de vista simbólico e social

Diante da situação de mudança, a partir da irrupção da doença, surgia outra pergunta, como o respectivo itinerário, do ponto de vista cultural, as atitudes eram tomadas no sentido de atualizar esta concepção de adoecimento, restando assim a reconstituição da origem da doença: por que aconteceu naquele momento, sob esta forma e nesse indivíduo? (ZEMPLÉNI, 1981).

A busca da origem da doença se refere especificamente ao contexto sociocultural em que essas representaçôes ocorrem a partir dos indivíduos que as produzem.

\section{Considerações finais}

A reinterpretação dos elementos da Biomedicina segundo as representações tradicionais de saúde e doença é a dinâmica dominante em São Domingos do Capim. A análise das categorias nosológicas demonstrou que o uso da categoria êmica "hanseníase" é indício desse processo, fomentado pela atuação efetiva do PSF, ocorrendo, assim, um declínio na utilização das demais categorias.

Como os usos de diferentes categorias de interpretação fundamentam diferentes usos sociais para o adoecimento (ZEMPLÉNI, 1982), a substituição das 
categorias êmicas mais tradicionais "lepra" e "feitiço", pela categoria "hanseníase",

fortemente vinculada à ação da Biomedicina, indica mudanças mais profundas nas dinâmicas das interações sociais engendradas por essas interpretações.

Para os setores mais escolarizados da sociedade, a identidade entre as categorias "lepra" e "hanseníase" leva à permanência das representações que concebem a doença como produto de condutas transgressivas. A doença seria um castigo divino às más condutas humanas e, portanto, é utilizada em proveito da regulação social dos comportamentos dos indivíduos. Nas áreas rurais e nos setores de baixa renda, a categoria êmica "hanseníase" é interpretada como uma nova doença, tal como a Aids. No entanto, não nos pareceu carregar todo o conjunto de significados associados à "antiga lepra", pois "tem cura" e não possui manifestações que deformam os corpos de seus portadores, incapacitando-os para o trabalho.

A contínua incorporação de elementos próprios dos modos de vida urbana, - a televisão, os celulares, as motocicletas, os antibióticos, os exames de laboratório, as ultrassonografias -, e sua progressiva valorização em detrimento da vida rural, considerada arcaica e atrasada, produzem mudanças mais profundas que se revelam nos modos como as doenças são interpretadas, num jogo em que categorias novas e velhas se alternam na construção do sentido para as experiências dos indivíduos.

A perspectiva pragmática e adaptativa com que amplos setores da sociedade brasileira conduzem suas vivências em um espaço social permeado pela mudança parece orientar os indivíduos à valorização dos elementos que identificam como capazes de permitir seu reconhecimento e sua inserção social.

Nas interpretações da doença, tal perspectiva parece estar presente. As atribuições causais que davam sentido à doença, seja ela a "mancha", a "lepra", o "feitiço" ou a "hanseníase", baseavam-se na associação desta com elementos da natureza (o pau, a terra, o cachorro, o capim peludo), do trabalho manual, do modo de vida e das condições de pobreza do mundo rural. Em oposição à cidade, aos medicamentos, aos exames médicos, à vida urbana, relacionados à saúde e à cura. Assim, a representação da hanseníase fundamenta-se sobre um sistema de representações de saúde e doença que se estrutura de forma paralela às oposições antigo-moderno e natureza-sociedade; a saúde sendo determinada pela proximidade dos indivíduos com o moderno, com a vida urbana e com a medicina dos fármacos e das tecnologias sofisticadas. A doença fica, assim, vinculada ao antigo e à natureza, ambos lugares da vida rural, do trabalho 
árduo, dos perigos das plantas e dos animais, das forças ocultas da magia, da desassistência, do desamparo e da pobreza. Por isso, as doenças dos "antigos" - a "lepra" e o "feitiço" - têm cada vez menos lugar hoje. E hoje, o que há é uma "nova doença" - a "hanseníase" - que tem cura e que não mais coloca os acometidos na prisão da culpa pelas transgressóes, no isolamento social e na iminência da morte anunciada.

A incorporação da categoria nosológica êmica "hanseníase" no repertório interpretativo da população de São Domingos do Capim-PA é indício das mudanças pelas quais a sociedade atravessa. A ansiedade dos doentes, observadas no consultório, parece ser o indício de uma preocupação em diferenciar as manifestações cutâneas mais simples daquela "doença nova", que exige um período de tratamento prolongado e atenção especial dos profissionais de saúde.

O reconhecimento da existência da cura para a "nova doença" é uma questão crucial nas interpretaçôes da enfermidade, que coloca em xeque o discurso da Biomedicina. O desenvolvimento dos chamados quadros reacionais (episódios inflamatórios) que podem se manifestar no doente antes, durante e depois do tratamento poliquimioterápico, desperta a desconfiança no diagnóstico, na possibilidade efetiva de cura e na segurança dos medicamentos utilizados. Se por um lado, os quadros reacionais constituem para os doentes, evidências dos limites da Biomedicina; por outro lado, o próprio sistema médico reconhece que a resolução dessas manifestações representa um desafio para a pesquisa científica sobre hanseníase (CUNHA, 2002; SARNO, 2003).

A atenção básica de saúde oferece tratamento para as manifestações clínicas, visando, sobretudo impedir a transmissão do bacilo e a sua destruição (BRASIL/ MS, 2002). Para os estados reacionais graves e para as sequelas, o tratamento ocorre em hospitais e em unidades de referência especializada. Os esquemas terapêuticos encontram-se disponíveis apenas nas unidades de referência, acessadas muitas vezes com dificuldade pelos doentes, que frequentemente continuam invisíveis e isolados no meio rural.

Diante do quadro configurado em São Domingos do Capim, que guarda semelhanças inegáveis com outros locais da Amazônia e do Brasil, que contribuições a antropologia da doença pode fornecer na perspectiva de estabelecer um controle da endemia hansênica? Parafraseando Nicole Sindzingre (1986) e Dominique Buchillet (1991), diríamos que o conhecimento antropológico não 
se constitui em mero "luxo cognitivo", mas uma condição essencial para que os objetivos a serem alcançados, com a implementação de programas médicosanitários, possam se efetivar.

O conhecimento antropológico sinaliza, antes de tudo, que a realidade do adoecimento não se reduz à descrição de indicadores epidemiológicos e suas relações com condicionantes socioeconômicos. $\mathrm{O}$ consenso científico construído a respeito da hanseníase, que estabelece que sua prevalência está associada às condições de pobreza, mascara a complexidade dos processos de produção social da doença, que não podem ser reduzidos à sua dimensão sócio-econômica. Desta forma, compreender as representações da hanseníase significa recolocar a doença entre os eventos capazes de suscitar as interpretações que orientam as experiências dos indivíduos, fazendo uso dos repertórios simbólicos que sua sociedade lhes oferece. Pressupõe, ainda, entender as próprias intervenções médico-sanitárias como componentes ativos dessa dinâmica.

Ao valorizar as experiências de adoecimento dos indivíduos imersos em um campo simbólico, a Antropologia possibilita que aspectos negligenciados pela Biomedicina e pelas políticas de saúde deixem seu lugar de invisibilidade social e política e possam compor um quadro mais amplo da realidade como fundamento necessário à construção de intervenções mais efetivas num diálogo plural e interdisciplinar.

\section{Referências}

BRASIL. MINISTÉRIO DA SAÚDE. Secretaria de Políticas de Saúde. Departamento de Atenção Básica. Guia para o controle da hanseníase. 3 ed. Brasília: Ministério da Saúde, 2002.

. Sistema Nacional de Vigilância em Saúde: relatório de situação - Pará. Brasília: Ministério da Saúde, 2005.

- Vigilância em saúde: situação epidemiológica da hanseníase no Brasil. Brasília: Ministério da Saúde, 2008.

BUCHILLET, Dominique. A antropologia da doença e os sistemas oficiais de saúde. In: Medicinas tradicionais e medicina ocidental na Amazônia. Belém: MPEG, 1991a. p. 21-44.

. Impacto do contato sobre as representaçôes tradicionais da doença e de seu tratamento: uma introdução. In: . Medicinas tradicionais e medicina ocidental na Amazônia. Belém: MPEG, 1991b. p. 161-174.

. Tuberculose, cultura e saúde pública. Serie Antropologia da UNB, Brasília, n. 273, p.1-18, 2000. 

Rio de Janeiro, v. 15, Supl., p. 177-201, 2005.

CAYRES, Maria Guilhermina V. Nazarenos e marias do rio Capim: análise de gênero em uma comunidade amazônica. 1999. 225f. Dissertação (Mestrado em Planejamento do Desenvolvimento) - Núcleo de Altos Estudos Amazônicos, Universidade Federal do Pará, Belém.

CORMIER, Loretta. Um aroma no ar: a ecologia histórica das plantas anti-fantasma entre os Guajá da Amazônia. Mana, Rio de Janeiro, v. 11, n. 1, p.129-154, abr. 2005.

COSTA, Maria Clélia L. A cidade e o pensamento médico: uma leitura do espaço urbano. Mercator, Fortaleza, ano 1, n. 2, p. 61-69, 2002.

CUNHA, Ana Zoé S. Hanseníase: aspectos da evolução do diagnóstico, tratamento e controle. Ciência \& Saúde Coletiva, v. 7, n. 2, p. 235-242, 2002.

DOZON, Jean-Pierre; SINDZINGRE, Nicole. Pluralisme thérapeutique et médecine traditionnelle en Afrique contemporaine. Prévenir, Marseille, n. 12 (La santé dans lê tiersmonde), p. 43-52, 1986.

FAINZANG, Sylvie. La maladie, un objet pour l'anthropologie sociale. Ethnologies Comparées, Montpellier, n. 1, out. 2000. Disponível em: <http://recherche.univ-montp3.fr/mambo/cerce/r1/ s.f.htm>. Acesso em: 10 jan. 2008.

FOUCAULT, Michel. Microfísica do poder. Rio de Janeiro: Graal, 1984.

LANGDON, Esther Jean. A doença como experiência: a construção da doença e o seu desafio para a prática médica. Conferência 30 anos Xingu, São Paulo, 1995. Disponível em: http:// www.cfh.ufsc.br/nessi/. Acesso em: 20 ago. 2006.

NUNES, Everardo Duarte. Saúde Coletiva: história e paradigmas. Interface - Comunicação, Saúde e Educação, n. 3, p.107-116, 1998.

NUNES, Mônica de Oliveira et al. O agente comunitário de saúde: construção da identidade desse personagem híbrido e polifônico. Cadernos de Saúde Pública, Rio de Janeiro, v.18, n. 6, p. 1.639-1.646, 2002.

PARÁ. Secretaria de Estado de Planejamento, Orçamento e Finanças. Estatística Municipal - São Domingos do Capim. Belém: SEPOF, 2008.

SARNO, Euzenir Nunes. A hanseníase no laboratório. História, Ciência e Saúde-Manguinhos, Rio de Janeiro, v.10, supl. 1, p. 277-290, 2003.

RAYNAUT, Claude. L'anthropologie de la santé, carrefour de questionnements: l'humain et le natural, individuel et le social. Ethnologies Comparées, Montpellier, n. 3, out. 2001. Disponível em: <http://recherche.univ-montp3.fr/mambo/cerce/r3/c.r.htm>. Acesso em: 10 jan. 2008.

SINDZINGRE, Nicole. La nécessité du sens. In: AUGÉ, Marc; HERZLICH, Claudine (Org.). Le sens du mal: anthropologie, histoire et sociologie de la maladie. Paris: Archives Contemporaines, 1986, p. 92-122. (Ordres Sociaux). 
SINDZINGRE, Nicole; ZEMPLÉNI, Andras. Modèles et pragmatique, activation et répétition: réflexions sur la causalité de la maladie chez les Senoufo de Côte d'Ivoire. Social Science \& Medicine. Part B: Medical Anthropology, v. 15, n. 3, p. 279-293, jul. 1981.

TALHARI, Sinésio; CRUZ, Carlos Alberto V. da; CARNEIRO, Irna Carla do Rosário de Souza. Hanseníase. In: LEÃO, Raimundo N. Q. de (Coord.). Doenças infecciosas e parasitárias: enfoque amazônico. Belém: Cejup; UEPA; Instituto Evandro Chagas, 1997.

ZEMPLÉNI, Andras. Anciens et nouveaux usages sociaux de la maladie en Afrique. Archives des Sciences Sociales des Religions, Paris, v. 4, n. 1, p. 5-19, 1982.

. A “doença” e suas "causas". Tradução Paula Morgado. Cadernos de Campo, São Paulo, n. 4, p. 137-163, 1994.

\section{Notas}

${ }^{1}$ O termo "Biomedicina" se refere à Medicina Ocidental Contemporânea. Adota-se, neste trabalho, a designação proposta por Luz (1988) e Camargo Jr. (2005), que escolheram este termo pela concisão e por refletir mais adequadamente a vinculação desta racionalidade com o conhecimento produzido por disciplinas científicas do campo da Biologia, com a ênfase no conceito moderno de doença e as implicações desse conceito na diagnose e terapêutica.

${ }^{2}$ Segundo o relatório do Programa Nacional de Controle da Hanseníase (BRASIL/MS, 2008), os coeficientes de detecção de casos novos registrados nos estados da Amazônia Legal em 2007 mostram que há um comprometimento da Amazônia Legal em relação à hanseníase, tendo em vista que a região possuía 12,9\% da população do Brasil e concentrava 38,9\% (15.532) dos casos novos detectados no país.

${ }^{3}$ O Programa de Saúde da Família é uma estratégia de atenção básica de saúde, implantada pelo Ministério da Saúde a partir de 1994, sendo operacionalizada por equipes integradas por um médico, um enfermeiro, um técnico de enfermagem e dez agentes comunitários de saúde que atuam numa área adscrita para uma população de aproximadamente 3.000 pessoas. Sobre assunto consultar: www. saude.gov.br/dab/atençãobasica/phb\#saude da família. Acessado em: 22 abr. 2007.

${ }^{4}$ Segundo dados do Ministério da Educação e da Secretaria de Estado de Educação, a matrícula no ensino fundamental em São Domingos do Capim teve um incremento de 9,2\% entre os anos de 1996 e 2006. O ensino médio apresentou aumento de $217,1 \%$, indicando que um contingente expressivo concluiu o ensino fundamental no período (PARÁ, 2008).

${ }^{5}$ Cetoconazol é um medicamento antimicótico ou antifúngico que pode ser utilizado sistêmica ou topicamente (cremes e xampus) em manchas provocadas por fungos. 
Social Representations and Hansen's Disease in São Domingos do Capim, State of Pará: a Study in Brazilian Amazon

This study analyzes the social representations of Hansen's disease in São Domingos do Capim-PA, from the perspective of the anthropology of disease. The representations are understood as socially constructed dynamic structures that underlie the actions of individuals and groups in the resolution of episodes of illness and the production of meaning to the experience of illness. To understand the logic of the interpretations of the disease, were reconstituted the therapeutic itineraries of patients from data collected in field observations, conducted over four years, and narrative interviews with patients, family and community health workers. Were deducted four emic nosological categories regarding symptoms of Hansen's disease - "spots", "leprosy", "spell” and "leprosy" - that constitute the repertoire from which the interpretations and practices are formulated. The use of different categories occurs according to local schemes that allow the evaluation of personal and social contexts of the disease outbreak in a dynamic, articulating the perceptions of patients and their families, interpretations and diagnostic approach of traditional healers and practitioners of Biomedicine. The study shows that the interpretative repertoire and therapeutic means of Biomedicine are reinterpreted by patients, according to the logic of representations and practices of local health and that the control of leprosy requires understanding the social dynamics involved in the interpretation and practice of disease in order to enable the establishment of a dialogical relationship between health professionals and local actors.

> Key words: Hansen's disease, social representation, therapeutic itineraries. 